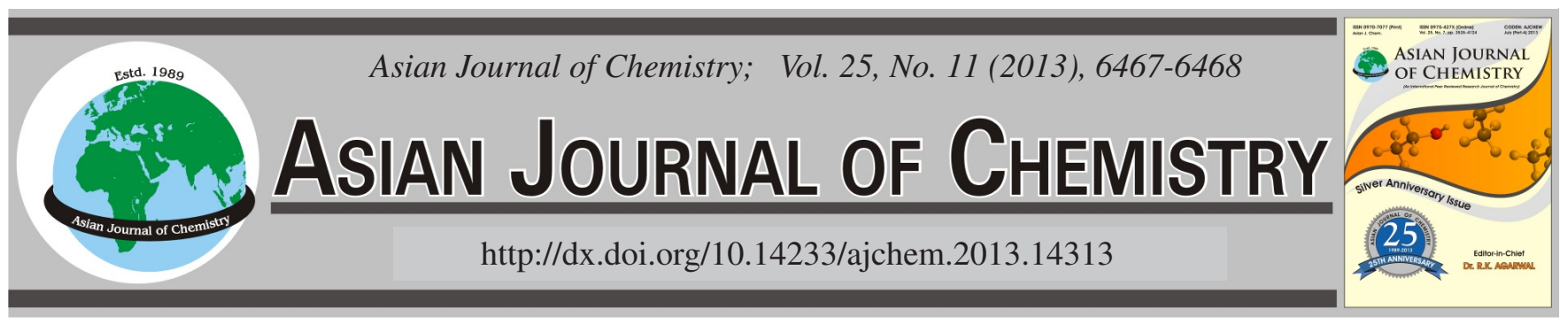

NOTE

\title{
Synthesis and Supramolecular Structure of 4,4',6,6'-Tetrachloro-2,2'- [(decane-1,10-diyldioxy)bis(nitrilomethylidyne)]diphenol
}

\author{
Wen-Kui Dong ${ }^{*}$, Xiang Li, Jun-Jiang Wu, Yang Zhang and XiaO-Lu Tang
}

School of Chemical and Biological Engineering, Lanzhou Jiaotong University, Lanzhou 730070, P.R. China

*Corresponding author: E-mail: dongwk@126.com

(Received: 16 July 2012;

Accepted: 14 May 2013)

AJC-13500

\begin{abstract}
A new salen-type bisoxime compound, 4,4',6,6'-tetrachloro-2,2'-[(decane-1,10-diyldioxy)bis(nitrilomethylidyne)]diphenol, has been synthesized and characterized structurally. In each molecule, there is a trans configuration with respect to the methylidene unit. The two phenyl rings in each molecule are paralle to each other, with a perpendicular interplanar spacing of $c a$. $6.583(2) \AA$. In the crystal structure, each

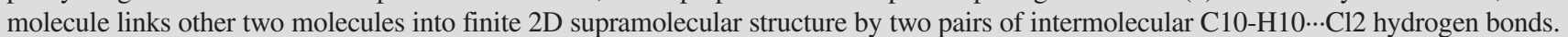

Key Words: Salen-type bisoxime, Synthesis, Supramolecular structure.
\end{abstract}

Salen-type compound and its derivatives have played a significant role in the development of the coordination chemistry as they are one of the most important mixed-donor ligands in the modern coordination chemistry and these compounds have caused growing concern because of their strong coordination capability and important properties, such as diverse biological activities ${ }^{1-3}$, synthetic and catalytic activities ${ }^{4,5}$, magnetic properties ${ }^{6}$ and supramolecular architectures $^{7}$. In order to extend our work on supramolecular interactions of salen-type bisoxime compound, we reported the synthesis and crystal structure of the title compound.

3,5-Dichloro-2-hydroxybenzaldehyde was purchased from Alfa Aesar and used without further purification. 1,10-Bis(aminooxy)decane was synthesized according to an analogous method reported earlier. ${ }^{8}$. The other reagents and solvents were analytical grade reagents from Tianjin Chemical Reagent Factory. C, H and $\mathrm{N}$ analyses were carried out with a $\mathrm{GmbH}$ VariuoEL V3.00 automatic elemental analyzer. X-ray single crystal structure was determined on a Bruker Smart 1000 CCD area detector. Melting points were measured by the use of a microscopic melting point apparatus made in Beijing Taike Instrument Limited Company and the thermometer was uncorrected.

4,4',6,6'-Tetrachloro-2,2'-[(decane-1,10-diyldioxy) bis(nitrilomethylidyne)]diphenol was synthesized according to an analogous method reported earlier ${ }^{9,10}$. To an ethanol solution ( $5 \mathrm{~mL}$ ) of 3,5-dichloro-2-hydroxybenzaldehyde (38.2 mg, 0.2 mmol) was added an ethanol solution $(5 \mathrm{~mL}$ ) of 1,10-bis-(aminooxy)decane $(20.4 \mathrm{mg}, 0.1 \mathrm{mmol})$. The reaction mixture was stirred at $328 \mathrm{~K}$ for $4 \mathrm{~h}$. The formed precipitate was separated by filtrationand washed successively with ethanol and $n$-hexane. The product was dried under vacuum to yield $32.9 \mathrm{mg}$ of the title compound. Yield, $59.8 \%$. m.p. 364-365 K. anal. calcd. for $\mathrm{C}_{24} \mathrm{H}_{28} \mathrm{C}_{14} \mathrm{~N}_{2} \mathrm{O}_{4}$ : C, 52.38; H, 5.13; N, 5.09; Found: C, 52.71; H, 5.20; N, 4.97.

Colourless block-shaped single crystals suitable for $\mathrm{X}$-ray diffraction studies were obtained after two weeks by slow evaporation from acetone/acetonitrile (1:4) solution of the title compound.

X-Ray structure determination: The single crystal of the title compound, with approximate dimensions of $0.43 \times$ $0.22 \times 0.09 \mathrm{~mm}$ was placed on a Bruker Smart 1000 diffractmeter equipped with Apex CCD area detector. The diffraction data were collected using a graphite monochromated $\mathrm{MoK}_{\alpha}$ radition $(\lambda=0.71073 \AA)$ at $298(2) \mathrm{K}$. The structure was solved by using the program SHELXS-97 and Fourier difference techniquesand refined by full-matrix least-squares method on $\mathrm{F}^{2}$ using SHELXL-97. Details of the data collection and refinements of the title compound are given in Table- 1 . The non-hydrogen atoms were refined anisotropically. Hydrogen atoms were added theoretically. CCDC: 712163.

$\mathrm{X}$-ray crystallographic analysis revealed the crystal structure of the title compound. And the structure is shown in Fig. 1. Selected bond distances and angles are listed in Table-2. The single crystal structure of the title compound is only built up by the $\mathrm{C}_{24} \mathrm{H}_{28} \mathrm{~N}_{2} \mathrm{O}_{4} \mathrm{Cl}_{4}$ molecule. In each molecule, there is a trans configuration with respect to the methylidene unit. The two phenyl rings in each molecule are parallel to each other, with C1-O1-N1-C7 torsion angles of -179.2 (8) ${ }^{\circ}$ and a perpendicular 
TABLE-2

SELECTED BOND DISTANCES $(\AA)$ AND ANGLES $\left({ }^{\circ}\right)$ FOR THE TITLE COMPOUND

\begin{tabular}{|c|c|c|c|c|c|}
\hline Bond & Lengths & Bond & Lengths & Bond & Lengths \\
\hline $\mathrm{N}(1)-\mathrm{C}(6)$ & $1.272(12)$ & $C(1)-C(2)$ & $1.498(14)$ & $\mathrm{C}(7)-\mathrm{C}(12)$ & $1.395(14)$ \\
\hline $\mathrm{N}(1)-\mathrm{O}(1)$ & $1.405(10)$ & $C(2)-C(3)$ & $1.471(13)$ & $\mathrm{C}(7)-\mathrm{C}(8)$ & $1.430(13)$ \\
\hline $\mathrm{O}(1)-\mathrm{C}(1)$ & $1.433(11)$ & $C(3)-C(4)$ & $1.513(13)$ & $\mathrm{C}(8)-\mathrm{C}(9)$ & $1.402(14)$ \\
\hline $\mathrm{O}(2)-\mathrm{C}(8)$ & $1.368(11)$ & $C(4)-C(5)$ & $1.495(14)$ & $\mathrm{C}(9)-\mathrm{C}(10)$ & $1.359(14)$ \\
\hline $\mathrm{C}(11)-\mathrm{C}(9)$ & $1.731(10)$ & $C(5)-C(5)$ & $1.495(19)$ & $\mathrm{C}(10)-\mathrm{C} 11)$ & $1.401(12)$ \\
\hline $\mathrm{C}(12)-\mathrm{C}(11)$ & $1.736(9)$ & $C(6)-C(7)$ & $1.449(14)$ & $\mathrm{C}(11)-\mathrm{C}(12)$ & $1.338(13)$ \\
\hline Bond & Angles & Bond & Angles & Bond & Angles \\
\hline $\mathrm{C}(6)-\mathrm{N}(1)-\mathrm{O}(1)$ & 111.3(8) & $C(12)-C(7)-C(8)$ & $116.5(9)$ & $\mathrm{C}(8)-\mathrm{C}(9)-\mathrm{Cl}(1)$ & 119.1(8) \\
\hline $\mathrm{N}(1)-\mathrm{O}(1)-\mathrm{C}(1)$ & $109.7(7)$ & $C(12)-C(7)-C(6)$ & $120.9(9)$ & $\mathrm{C}(9)-\mathrm{C}(10)-\mathrm{C}(11)$ & $119.5(9)$ \\
\hline $\mathrm{O}(1)-\mathrm{C}(1)-\mathrm{C}(2)$ & $107.3(8)$ & $\mathrm{C}(8)-\mathrm{C}(7)-\mathrm{C}(6)$ & $122.6(9)$ & $\mathrm{C}(12)-\mathrm{C}(11)-\mathrm{C}(10)$ & $120.2(9)$ \\
\hline $\mathrm{C}(3)-\mathrm{C}(2)-\mathrm{C}(1)$ & $116.2(8)$ & $\mathrm{O}(2)-\mathrm{C}(8)-\mathrm{C}(9)$ & $119.6(8)$ & $\mathrm{C}(12)-\mathrm{C}(11)-\mathrm{Cl}(2)$ & $121.2(7)$ \\
\hline $\mathrm{C}(2)-\mathrm{C}(3)-\mathrm{C}(4)$ & $114.6(8)$ & $\mathrm{O}(2)-\mathrm{C}(8)-\mathrm{C}(7)$ & $120.9(9)$ & $\mathrm{C}(10)-\mathrm{C}(11)-\mathrm{Cl}(2)$ & $118.6(7)$ \\
\hline $\mathrm{C}(5)-\mathrm{C}(4)-\mathrm{C}(3)$ & $116.1(8)$ & $\mathrm{C}(9)-\mathrm{C}(8)-\mathrm{C}(7)$ & $119.5(9)$ & $\mathrm{C}(11)-\mathrm{C}(12)-\mathrm{C}(7)$ & $123.2(9)$ \\
\hline $\mathrm{C}(4)-\mathrm{C}(5)-\mathrm{C}(5)$ & $117.2(11)$ & $\mathrm{C}(10)-\mathrm{C}(9)-\mathrm{C}(8)$ & $121.0(9)$ & & \\
\hline $\mathrm{N}(1)-\mathrm{C}(6)-\mathrm{C}(7)$ & $120.1(9)$ & $\mathrm{C}(10)-\mathrm{C}(9)-\mathrm{Cl}(1)$ & $119.9(8)$ & & \\
\hline
\end{tabular}

TABLE-1

CRYSTAL DATA AND STRUCTURE REFINEMENT FOR THE TITLE COMPOUND

\begin{tabular}{ll}
\hline Empirical formula & $\mathrm{C}_{24} \mathrm{H}_{28} \mathrm{~N}_{2} \mathrm{O}_{4} \mathrm{Cl}_{4}$ \\
Formula weight & 550.28 \\
Temperature $(\mathrm{K})$ & $298(2)$ \\
Wavelength $(\AA)$ & 0.71073 \\
Crystal system & Triclinic \\
Space group & $\mathrm{P}-1$ \\
Cell dimensions, $(\AA, \mathrm{deg})$ & $\mathrm{a}=4.5804(6), \mathrm{b}=7.9141(11), \mathrm{c}$ \\
& $=17.9692(18), \alpha=84.2770(10)$, \\
& $\beta=86.437(2), \gamma=80.8340(10)$ \\
Volume, $\AA^{3}$ & $639.15(14)$ \\
$Z$ & 1 \\
Density (calculated), $\mathrm{mg} / \mathrm{m}^{3}$ & 1.430 \\
Absorption coefficient, $\mathrm{mm}^{-1}$ & 0.497 \\
$\mathrm{~F}(000)$ & 286 \\
Index ranges & $-5 \leq \mathrm{h} \leq 5,-9 \leq \mathrm{k} \leq 7,-16 \leq 1 \leq 21$ \\
Reflections collected & $2889 / 2079[R(\mathrm{int})=0.0529]$ \\
Independent reflections & 930 \\
Data/restraints/parameters & $2079 / 0 / 155$ \\
Goodness of fit indicator & 1.041 \\
$\mathrm{R}[\mathrm{I}>2 \sigma(\mathrm{I})]$ & $\mathrm{R}_{1}=0.0529, \mathrm{wR}_{2}=0.1214$ \\
Largest diff. peak and hole, $\mathrm{e} \cdot \AA^{-3}$ & 0.803 and -0.583 \\
\hline
\end{tabular}

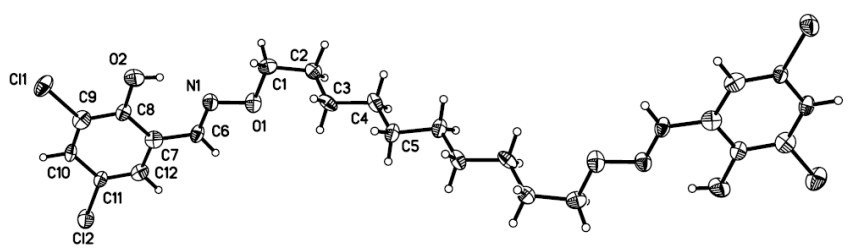

Fig. 1. Molecule structure of the title compound with atom numbering scheme. Displacement ellipsoids for non-H atoms are drawn at the $30 \%$ probability level

interplanar spacing of $c a$. 6.583(2) $\AA$. There are two intramolecular $\mathrm{O} 2-\mathrm{H} 2 \cdots \mathrm{N} 1$ hydrogen bonds between the hydroxyl groups and the oxime $\mathrm{N}$ atoms in each molecule (Table-3). In the crystal structure, each molecule links other two mole-cules into finite 2D supramolecular structure by two pairs of intermolecular C10-H10 … Cl2 hydrogen bonds (Fig. 2).
TABLE-3

HYDROGEN BOND $\left(\AA{ }^{\circ},{ }^{\circ}\right)$ FOR THE TITLE COMPOUND

\begin{tabular}{|c|c|c|c|c|}
\hline D-H $\cdots A$ & $\mathrm{~d}(\mathrm{D}-\mathrm{H})$ & $\mathrm{d}(\mathrm{H} \cdots \mathrm{A})$ & $\angle \mathrm{DHA}$ & $d(D \cdots A)$ \\
\hline $\mathrm{O} 2-\mathrm{H} 2 \cdots \mathrm{N} 1$ & 0.82 & 1.89 & 146 & $2.609(3)$ \\
\hline $\mathrm{C} 10-\mathrm{H} 10 \cdots \mathrm{Cl} 2$ & 0.93 & 2.88 & 166 & $3.794(3)$ \\
\hline
\end{tabular}

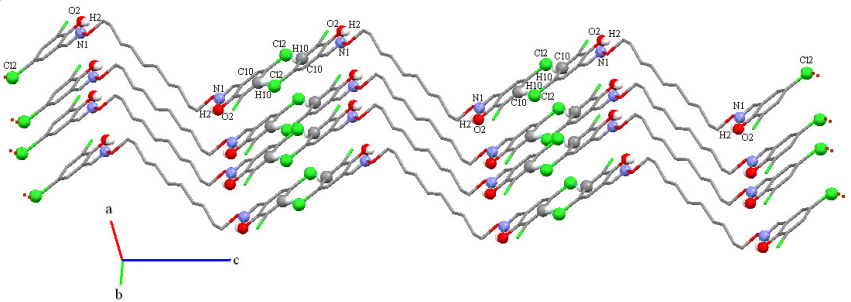

Fig. 2. A perspective view of the intramolecular and intermolecular hydrogen-bond interactions

\section{ACKNOWLEDGEMENTS}

This work was supported by the Fundamental Research Funds for the Gansu Province Universities (212086) and the Science and Technology support funds of Gansu Province (212249), which are gratefully acknowledged.

\section{REFERENCES}

1. S. Koizumi, M. Nihei, M. Nakano and H. Oshio, Inorg. Chem., 44, 1208 (2005).

2. C. Boskovic, R. Bircher, P.L.W. Tregenna-Piggott, H.U. Güdel, C. Paulsen, W. Wernsdorfer, A.L. Barra, E. Khatsko, A. Neels and H. StoeckliEvans,, J. Am. Chem. Soc., 125, 14046 (2003).

3. H. Oshio, M. Nihei, S. Koizumi, T. Shiga, H. Nohiri, M. Nakano, N. Shirakawa and M. Akatsu, J. Am. Chem. Soc., 127, 4568 (2005).

4. S.A. Mohand, A. Levina and J. Muzart, J. Chem. Res. (S), 25, 2051 (1995).

5. J.E. Campbell, H. Zhou and T.S. Nguyen, Org. Lett., 3, 2391 (2001).

6. J. Nishijo, C. Okabe, O. Oishi and N. Nishi, Carbon, 44, 2943 (2006).

7. S. Akine, T. Taniguchi, W.K. Dong, S. Masubuchi and T. Nabeshima, J. Org. Chem., 70, 1704 (2005).

8. W.K. Dong, G. Wang, S.S. Gong, J.F. Tong, Y.X. Sun and X.H. Gao, Transition Met. Chem., 37, 271 (2012).

9. W.K. Dong, J.Y. Shi, J.K. Zhong, Y.Q. Tian and J.G. Duan, Chinese J. Inorg. Chem., 24, 10 (2008).

10. W.K. Dong, J.Y. Shi, J.K. Zhong, Y.X. Sun and J.G. Duan, Struct. Chem., 19, 95 (2008) 